\title{
Numerical Simulation and Experimental Study on Noise Prediction for Engine
}

\author{
Yong-gang Xiong \\ The college of Mechanical, Hunan \\ University of Technology, Zhuzhou \\ Hunan 412008, China \\ xygyxj@163.com
}

\author{
Li Shun \\ The college of Mechanical, Hunan \\ University of Technology, Zhuzhou \\ Hunan 412008, China \\ jellykiwifruit@163.com
}

\author{
Tian-jun Xia \\ The college of Mechanical, Hunan \\ University of Technology, Zhuzhou \\ Hunan 412008, China \\ boy_xia@yahoo.com.cn
}

\begin{abstract}
A motorcycle engine shell is taken as the research object in the paper in order to reduce the noise radiation of motorcycle engine. The noise radiation of the engine shell is analyzed by the finite element method and boundary element method ( FEM / BEM ), and the frequency range of the noise radiation and the critical region are determined. Combining with sound intensity test, it is proved that the calculation result of the software is correct. According to the simulation results, the engine shell structure was optimized, and the noise radiation of the optimized model was predicted. Comparing the noise test before and after the model optimization, the results show that the optimized engine shell surface radiated noise is reduced about $4 \mathrm{~dB}$.
\end{abstract}

Keywords-FEM/BEM; engine; noise prediction; noise control

\section{INTRODUCTION}

Engine, as the heart of the various modes of transport, like aircraft, ships, automobiles and motorcycles, has taken great convenience to humans with the characteristic of light weight and high thermal efficiency. With the development of social and the improvement of people's living standards, the engine noise control requirements also rise, such as good noise, vibration, and riding comfort (noise, vibration and harshness Abbreviated to $\mathrm{NVH}^{[1]}$ ) is the standard to engine market. Motorcycle engine is a typical of shell parts, which has the small stiffness and the lightweight. Because of the vibration of the engine organism, it becomes the main source of the radiation noise. Besides it exposes to the air and contacts with the body directly, without any the deadening facilities. Thus researching for reducing the radiated noise of motorcycle engines will be imperative. Meanwhile the noise analysis and control for the engine shell type is also important.

The CAD / CAE analysis based on numerical simulation and the experiment study for test has become the main means of engine vibration and radiated noise. Finite element method and boundary element method are powerful tools to study the complex structure of acoustic coupling mechanism in numerical simulation ${ }^{[2]}$. The finite element analysis software ANSYS and the acoustic analysis software SYSNOISE also become favorable analysis software to predict the radiated noise ${ }^{[3-4]}$. The sound intensity measurement technique is the acoustic measurement techniques, which was used to measure

Foundation item: Support by Natural Science Fund project of Hunan Province "Study on Controlling and forecasting Noise Radiated from Engine (09JJ6074)”, and (2011FJ3201) the engine noise widely. Besides it has little impact to environment and reliable to access the characteristics of the engine radiated acoustic field. In this paper, using AWA6290 sound intensity measurement system to measure a motorcycle engine sound field, which verify the validity of the numerical results.

\section{BUILD THE FINITE ELEMENT MODEL AND MODAL ANALYSIS}

Using the 3D software Pro / Engineer build solid model of the engine shell. Then it needs to put the solid model into the finite element pre-processing software ANSA. Through cleaning-up the geometry, defining the material and meshing the model, the finite element model of the engine shell was established shown in Figure 1. Finite element model parameters are as follows: the unit length is $4 \mathrm{~mm}$; and it has 47164 tetrahedral element obtained from meshing method of 20 nodes and SOILD186 unit to the model; the engine shell material is a hard aluminum alloy and the parameter is

$$
\begin{aligned}
E & =70 G P a \\
\rho & =2.76 \mathrm{~g} / \mathrm{cm}^{3} \\
\mu & =0.3
\end{aligned}
$$

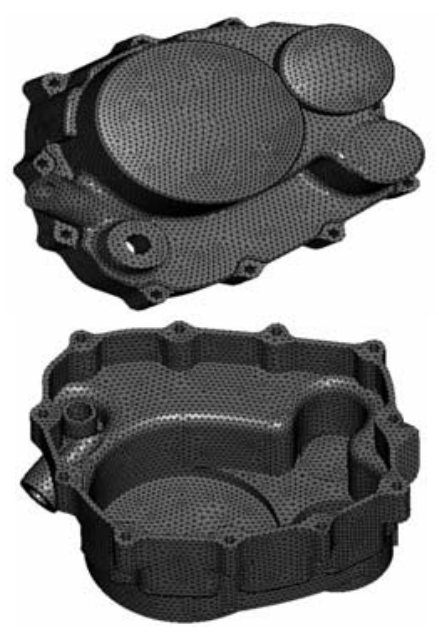

Fig.1 Finite element model of the engine shell 
Modal Analysis plays an important role in the engine vibration and noise reduction ${ }^{[5]}$. In order to design reasonable structure to avoid resonance frequency, the modal analysis of the engine shell is indispensable. As it is shown in Table 1, ANSYS is used to calculate the free mode of the finite element model, and the first eight order natural frequency of the non-rigid body is obtained in this paper.

TABLE 1. THE INHERENT FREQUENCY OF THE ENGINE SHELL

\begin{tabular}{ccccccccc}
\hline $\begin{array}{c}\text { Mode } \\
\text { numbe } \\
\mathrm{r}\end{array}$ & 1 & 2 & 3 & 4 & 5 & 6 & 7 & 8 \\
\hline $\begin{array}{c}\text { inheren } \\
\mathrm{t} \\
\text { freque } \\
\text { ncy/Hz }\end{array}$ & $\begin{array}{c}88 \\
2\end{array}$ & 1186 & 2105 & 2435 & 2634 & 2808 & 3267 & 3517 \\
\hline
\end{tabular}

\section{THE NOISE RADIATION ANALYSIS OF ENGINE SHELL} STRUCTURE

In order to simulate engine noise radiation of the shell in the actual operating conditions, ANSYS is used to transient analysis the shell model at the first step. The acceleration signal of the bolt is the boundary excitation conditions for the vibration test. The collected data was saved with a string of binary text file, and define a table parameter using“ Array Parameters-Define/Edit" in ANSYS. The data was read into the table through "Array Operations-Read From File". Constrain the DOF of the $\mathrm{y}$ direction, and the rotation of $\mathrm{x}$, z-direction.

After the transient analysis to the engine shell model, we need to extract the node response data of the surface of the shell structure through APDL to write finite element spectral analysis program, which is the boundary conditions of the shell surface for SYSNOISE calculation. Then the boundary element model of the engine shell radiation was established for noise prediction. The boundary element model only requires the mesh envelope of the engine, so the 3D model of the engine shell need be changed properly. Taking account the structure and size of the engine shell, the size of the re-meshing the surface solid model is $6 \mathrm{~mm}^{[6]}$. Besides a face field that distance $18 \mathrm{~cm}$ from the shell was built in the $y$ direction of the model. The theoretical analysis model for calculating of noise radiation was obtain, which used to calculate the external sound field of the structure. The theoretical analysis model for calculation of noise radiation is shown in Figure 2.

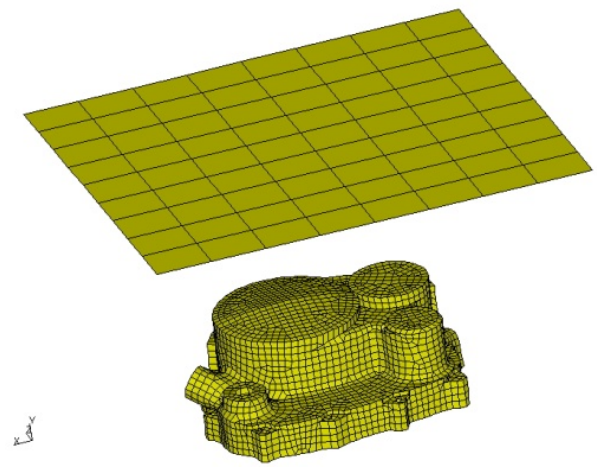

Fig. 2 The theoretical analysis model for calculation of noise radiation

The displacement data got from the result of transient analysis of the surface node was imported into SYSNOISE. Using the direct boundary element method, which type is "BEM-Direct-Collocation-Node-Exterior-coupled-UnbaffledAsymptotic-Frequency”. The noise radiation of the engine shell in SYSNOISE was calculated. Figure 3 shows the sound pressure contour maps of the engine shell surface radiated noise at $20 \mathrm{~Hz}-1600 \mathrm{~Hz}$. Comparison with the experimental test of the sound intensity cloud is shown in Figure 3.
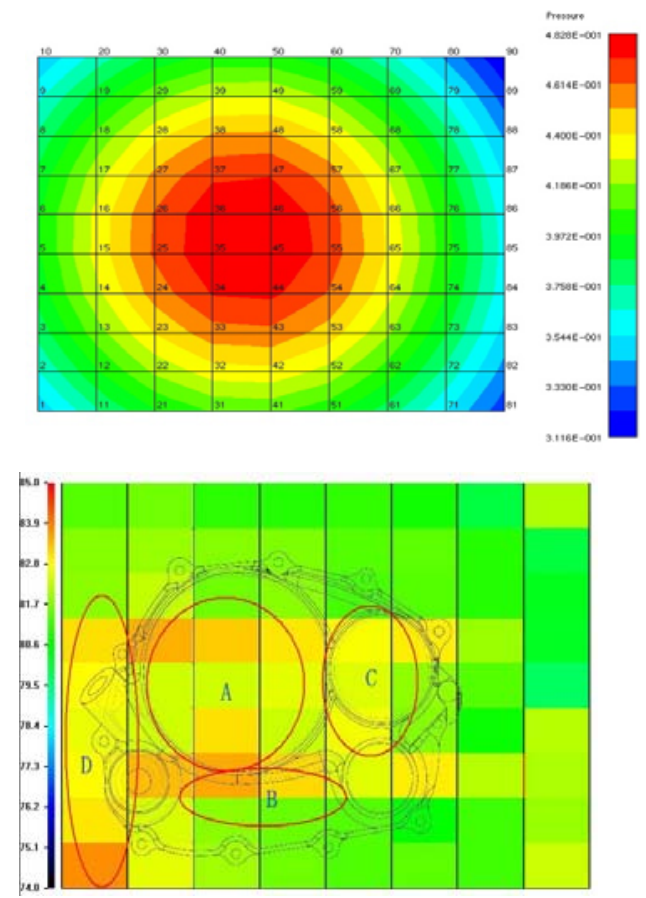

Fig.3 Sound contour map of the theoretical calculation and experimental result

The field point of the numerical simulation is corresponding to the grid points of the experimental test. Fig. 3 shows that the numerical simulation result is consistent with the experimental results of the noise source distribution compared with the theory result and the experimental result of the noise distribution. The distribution of the radiated noise incline to the left because of the influence of the exhaust pipe radiated noise at $D$ place. The place of the radiated noise of $A$ and $\mathrm{B}$ is higher than other place because the engine structure 
is flat and thin, which can radiated noise due to the vibration easily.

The comparison of the sound intensity frequency spectrum of the engine shell center for the result of experimental test and numerical calculation (1/3 octave) is shown in Figure 4.

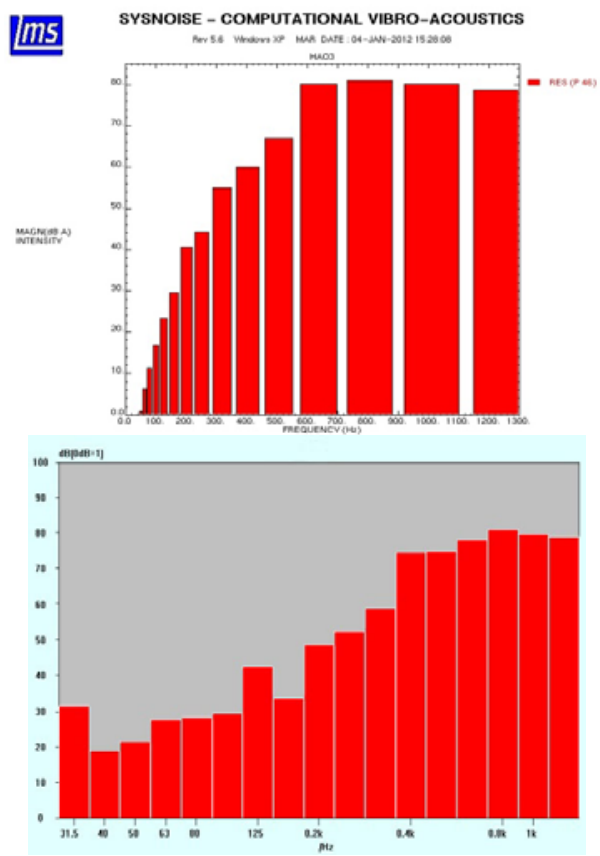

Fig.4 The A weighted sound intensity spectrum of the center point

From Fig.4, the calculated results are different from the experimental results in $31.5 \mathrm{~Hz}-600 \mathrm{~Hz}$, because of the effects of the low frequency noise in the engine inside, which let the result of the experimental is higher than calculated results. The calculated and experimental frequency in $600 \mathrm{~Hz}-1200 \mathrm{~Hz}$ are about $80 \mathrm{~dB}$, and the trend of the spectrum of the calculated result is the same with experimental, which indicates that the calculated results is consistent with the experimental results.

It's well known that the calculation results of the engine shell radiated noise contour maps by ANSYS and SYSNOISE are similar with the experimental test results in figure 3 and figure 4. Besides, the sound intensity spectrum of the calculation is also fit for experimental results in the field point, which proved that the numerical simulation is correct.

\section{THE STRUCTURE OPTIMIZATION AND ACOUSTIC RATING FOR ENGINE SHELL}

The noise radiated sources of the engine shell are the A and $B$ place from the analysis of Figure 3 . Increasing $2 \mathrm{~mm}$ thickness and changing the internal structure of the A place, the structure rigidity was improved. Meanwhile the vibration of the structure at B place was improved though 3 reinforcement, which can increase the resonance frequency and reduce the vibration amplitude, and achieve the purpose of reducing noise. Figure 5 shows the optimized finite element model of the engine shell.

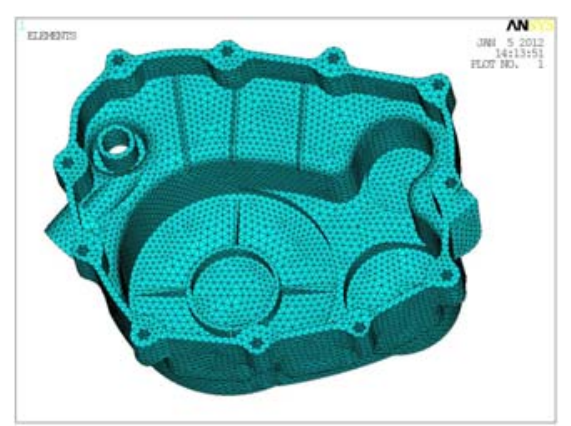

Fig.5 The element model of optimized engine shell

Using the finite element method and boundary element method to analyze the optimized model and simulate the radiated noise of the optimized engine shell with the same load and boundary conditions. The inherent frequency of the optimized engine shell is shown in Table 2.

TABLE 2. THE INHERENT FREQUENCY OF OPTIMIZED ENGINE SHELL

\begin{tabular}{ccccccccc}
\hline $\begin{array}{c}\text { Mode } \\
\text { number }\end{array}$ & 1 & 2 & 3 & 4 & 5 & 6 & 7 & 8 \\
\hline $\begin{array}{c}\text { Inhere } \\
\text { nt }\end{array}$ & 10 & 129 & 215 & 248 & 267 & 283 & 336 & 354 \\
freque & 07 & 6 & 6 & 7 & 7 & 6 & 9 & 9 \\
ncy/Hz & & & & & & & & \\
\hline
\end{tabular}

Table 2.shows that the inherent frequencies of the optimized engine shell structure are higher than before, and it is beneficial to the structure to avoid resonance frequency.

Figure 6 shows the contrast of output power of 1/3 octave for before and after optimization structure.

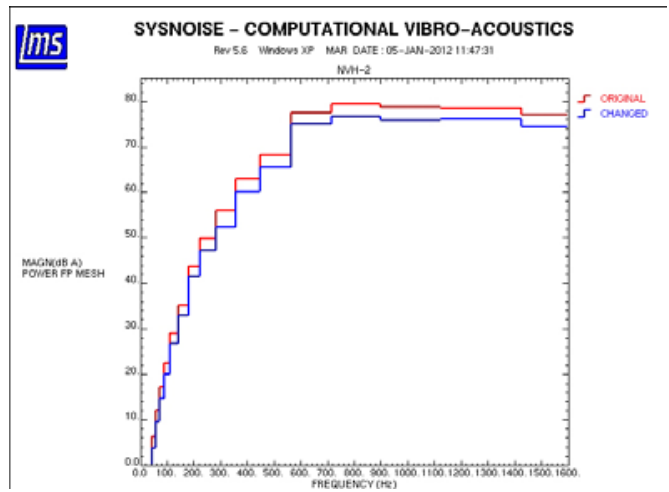

Fig.6 The contrast of output power for before and after structure

Fig.6 shows the sound power level of the entire frequency range of the optimized model has been reduced $4 \mathrm{~dB}$. The radiated noise of the engine shell had been reduced through optimization effectively.The frequency of the radiated noise source of the engine shell is in $600 \mathrm{~Hz}-1200 \mathrm{~Hz}$.

\section{CONCLUSION}

In this paper, the surface radiated noise of the engine shell structure was simulated using FEM/BEM method. The correctness of the numerical simulation results through the 
sound intensity measurement result was verified. The location of the radiated noise source of the engine shell was obtained and the frequency of noise is in $600 \mathrm{~Hz}-1200 \mathrm{~Hz}$. The surface radiated noise of the optimized model is obviously lower than original model, and the noise results was reduced about $4 \mathrm{~dB}$ after the optimization of the engine model with the increasing of thickness and tendons and the modify of structures.

\section{REFERENCES}

[1] X.Y. Ling: Study on the technology of noise control and prediction of the radiation noise for internal-combustion engine(Ph.D., Tianjin University, China 2006).
[2] D.Q. Yang, J.M. Zheng, D.Y. Wang and X.D. Jin:Shipbuilding of China,Vol. 43(4) (2002),p.32-37.

[3] J.H. Zhang, J.Han: Mechanical Systems and Signal Processing,Vol. 20(6) (2006),p.1400-1409

[4] L.T. Zhou, H.K. Li and Y.J. Guo:Noise and Vibration Control,Vol. 30(4) (2010),p.129-132.

[5] B.A. Song: Research on the Method of Low Noise Structure Dynamic Design for Diesel engin (Ph.D.,Tianjin University,China 2007).

[6] C.Z. Yang, K. Zhou and X.Chen:Journal of Jiangsu University, Vol. 31(4) (2010),p.393-396. 